\title{
Cadmium Accumulation Characteristics of F1 Hybrids by Reciprocal Hybridizing of Two Genotypes of Brassica juncea var. megarrhiza
}

\author{
Yumei Tan ${ }^{1, a}$, Ting Wang ${ }^{2, b}$, Huashan Lian ${ }^{3, c}$, Wei Jiang ${ }^{4, d}$ and Lijin Lin ${ }^{5, e^{*}}$ \\ ${ }^{1}$ College of Horticulture, Sichuan Agricultural University, Chengdu, Sichuan, China \\ ${ }^{2}$ Chengdu Academy of Agriculture and Forestry Sciences, Chengdu, Sichuan \\ ${ }^{3}$ Subcollege of Garden and Horticulture, Chendu Agricultural College, Chengdu, Sichuan, China \\ ${ }^{4}$ College of Chemistry and Life Science, Chengdu Normal University, Chengdu, Sichuan, China \\ ${ }^{5}$ Institute of Pomology and Olericulture, Sichuan Agricultural University, Chengdu, Sichuan, China \\ a2229809882@qq.com, b157829471@qq.com, c49939450@qq.com, d1399945180@qq.com, \\ ellj800924@163.com
}

${ }^{*}$ Corresponding author. Yumei Tan, Ting Wang and Huashan Lian contributed equally to this work.

\begin{abstract}
Keywords: Cadmium; Brassica juncea var. megarrhiza; Hybridizing
Abstract: To study whether the hybridizing could reduce the growth of F1 hybrids of vegetables under heavy metal stress, a pot experiment was carried out to investigate the cadmium $(\mathrm{Cd})$ accumulation characteristics of F1 hybrids by reciprocal hybridizing of two genotypes of Brassica juncea var. megarrhiza under Cd stress. The results showed that the reciprocal hybridizing of two genotypes of $B$. juncea var. megarrhiza had no obvious effects on biomass of F1 hybrids to some extent under $\mathrm{Cd}$ stress. The $\mathrm{Cd}$ contents in $\mathrm{F} 1$ hybrids of $B$. juncea var. megarrhiza were between two parents, which had no obvious reducing effects. Therefore, different genotypes of B. juncea var. megarrhiza hybridizing could had no obvious effects on enhancing biomass and reducing Cd content of $\mathrm{F} 1$ hybrids of B. juncea var. megarrhiza under Cd stress.
\end{abstract}

\section{Introduction}

Hybridization is a common technique used in plant breeding, and the F1 hybrids are superior to their parents in growth potential, fecundity, viability, yield and quality [1]. The F1 hybrids of kenaf have the more stronger resist and adapt to heavy metal stress compared with both parents [2]. The hybrid rape shows the higher resistance to low temperature stress, heavy metal stress and oxidative stress than its parents [3]. In recent years, by using different ecological climate of melon to hybrid (continental climate ecology group and the East Asian ecological group), a number of high quality, high yield, disease resistance, wide adaptability of new varietie are breeded. The masterials choosed from the different climatic-ecology zones for the parents of positive and negative hybrids will produce some varations under different climatic-ecology condition, especially the adaptability [1]. However, studies on heavy metal accumulation in F1 hybrids of vegetables from different climatic and ecological areas have not been reported.

Brassica juncea var. megarrhiza is the vegetable of Cruciferous Brassica herbaceous. In this study, two genotypes of $B$. juncea var. megarrhiza from two climate-ecology regions [the Central Subtropical-Long-Spring and Summer-Drought Zone (Chengdu, Sichuan, China) and the Mountain-Central Subtropical-Cold Zone in the Western Sichuan Basin (Ya'an, Sichuan, China)] [4] were collected as the materials to reciprocal hybridizing, and the cadmium $(\mathrm{Cd})$ accumulation characteristics of F1 hybrids were studied. The aim of this study was to confirm whether the hybridizing could reduce the Cd content in F1 hybrids of B. juncea var. megarrhiza under Cd stress, and provided a reference for other vegetable plants.

\section{Materials and Methods}

Materials Collection and Hybridization. Two genotypes of B. juncea var. megarrhiza plants were collected from Ya'an, Sichuan, China and Chengdu, Sichuan, China in March, 2015. The reciprocal 
hybridizing treatments were Ya'an male $\times$ Chengdu female and Chengdu male $\times$ Ya'an female. The reciprocal hybridizing method was the same as common hybridization breeding [5] and carried out in April, 2015. The day before B. juncea var. megarrhiza flowering, the female petals were poked with tweezers, and the anthers were removed and cleaned, then the female inflorescences were placed into plastic bags for isolation. At noon of the next day, the bags were opened, and the male pollens were applied onto the female styles, then the female inflorescences were again placed into plastic bags for isolation. When the seeds of B. juncea var. megarrhiza matured, they were collected, air-dried and stored separately at $4^{\circ} \mathrm{C}$.

The Inceptisol soil samples (purple soil in the Genetic Soil Classification of China) were collected from the Chengdu campus farm of Sichuan Agricultural University $\left(30^{\circ} 42^{\prime} \mathrm{N}, 103^{\circ} 51^{\prime} \mathrm{E}\right)$ in August 2015. The basic properties of the soil were $\mathrm{pH} 6.94$, organic matter $17.54 \mathrm{~g} / \mathrm{kg}$, total nitrogen 3.63 $\mathrm{g} / \mathrm{kg}$, total phosphorus $0.38 \mathrm{~g} / \mathrm{kg}$, total potassium $17.54 \mathrm{~g} / \mathrm{kg}$, alkali soluble nitrogen $195.00 \mathrm{mg} / \mathrm{kg}$, available phosphorus $6.25 \mathrm{mg} / \mathrm{kg}$ and available potassium $191.13 \mathrm{mg} / \mathrm{kg}$. The total Cd content was $0.103 \mathrm{mg} / \mathrm{kg}$, and the bioavailable Cd content was $0.022 \mathrm{mg} / \mathrm{kg}$.

Experimental Design. The soil samples were air-dried and passed through a $5 \mathrm{~mm}$ mesh sieve in August 2015, and then $3.0 \mathrm{~kg}$ of soil was weighed into each polyethylene pot $(15 \mathrm{~cm}$ tall, $18 \mathrm{~cm}$ diameter). Cd was added to make a final soil $\mathrm{Cd}$ concentration of $10 \mathrm{mg} / \mathrm{kg}$ [6] using a saturated heavy metal solution in the form of $\mathrm{CdCl}_{2} \cdot 2.5 \mathrm{H}_{2} \mathrm{O}$. The soils were mixed immediately and again after 4 weeks, during which time the soil moisture was maintained at $80 \%$. The seeds of B. juncea var. megarrhiza were sown separately in the farmland of the Chengdu campus farm in August 2015, and the soil moisture content was maintained at $80 \%$ of field capacity. The treatments of $B$. juncea var. megarrhiza were Ya'an (YA), Chengdu (CD), F1 hybrid of Ya' an male $\times$ Chengdu female (YC) and F1 hybrid of Chengdu male $\times$ Ya'an female (CY). In September 2015, three uniformly prepared $B$. juncea var. megarrhiza seedlings with four expanded euphyllas from each treatment were transplanted into each pot. Each treatment was repeated three times with $20 \mathrm{~cm}$ spacing between pots. The soil moisture content was maintained at $80 \%$ of field capacity until the plants were harvested. After four months, plants were harvested, and the roots, tubers and leaves were washed with tap water, and then further washed with deionized water and dried at $80^{\circ} \mathrm{C}$ to constant weight. The biomass was then measured of roots, tubers and leaves. The dried tissue samples were finely ground and sieved through a $0.149 \mathrm{~mm}$ mesh nylon sieve for chemical analysis. Samples $(0.5 \mathrm{~g})$ were digested in $\mathrm{HNO}_{3} / \mathrm{HClO}_{4}(4: 1, \mathrm{v} / \mathrm{v})$, and then the volume was brought to $50 \mathrm{~mL}$ with deionized water [7]. The $\mathrm{Cd}$ concentrations in roots, tubers and leaves were determined using an iCAP 6300 ICP-MS spectrometer (Thermo Scientific, Waltham, MA, USA). The translocation factor (TF) is defined as Cd content in shoots/Cd content in roots [8]. The heterosis rate of $\mathrm{F} 1$ hybrid $\mathrm{H}(\%)=(\mathrm{F} 1-\mathrm{P}) / \mathrm{P} \times 100, \mathrm{H}$ is heterosis, $F 1$ is the average of the $F_{1}$ hybrids, and $P$ is the average of the two parents [1].

Statistical Analyses. Statistical analyses were conducted using SPSS 13.0 statistical software (IBM, Chicago, IL, USA). Data were analyzed by one-way analysis of variance with least significant difference (LSD) at the $\mathrm{p}=0.05$ confidence level.

\section{Results and Discussion}

Biomass of Brassica juncea var. megarrhiza. The root, tuber and edible part biomasses of $B$. juncea var. megarrhiza from Chengdu were significantly lower than that from Ya'an (Table 1). However, The leaf biomass of $B$. juncea var. megarrhiza from Chengdu had no significant differences compared that from Ya'an. So, the biomass of B. juncea var. megarrhiza from Ya' an was higher than that from Chengdu, and also had more yield than that from Chengdu. The root biomass of YC F1 hybrid was between two parents, which was lower than that of Ya'an parent and higher than that of Chengdu parent. The tuber and leaf biomasses of YC F1 hybrid had no significant differences compared with both two parents. The edible part biomass of YC F1 hybrid had no significant differences compared with Ya'an parent, but significantly higher than that of Chengdu parent. The root biomass of CY F1 hybrid was significantly lower than that of Ya'an parent, but had no significant differences compared with Chengdu parent. The tuber, leaf and edible part biomasses of CY F1 hybrid had no significant differences compared with both two parents. The hybriding 
increased the root/shoot ratio of F1 hybrids, and was ranked as YC F1 hybrid $>$ CY F1 hybrid $>$ Ya'an parent $>$ Chengdu parent (Table 1).

The tuber, leaf and edible part biomasses of YC F1 hybrid had the heterosis compared with both two parents, and tuber and edible part biomasses of CY F1 hybrid also had the heterosis compared with both two parents (Table 2). However, the, root and leaf biomasses of CY F1 hybrid had the hybrid weakness compared with both two parents.

Table 1 Biomass of Brassica juncea var. megarrhiza

\begin{tabular}{|c|c|c|c|c|c|}
\hline Treatments & $\begin{array}{c}\text { Roots } \\
\text { (g/plant) }\end{array}$ & $\begin{array}{c}\text { Tubers } \\
\text { (g/plant) }\end{array}$ & $\begin{array}{c}\text { Leaves } \\
\text { (g/plant) }\end{array}$ & $\begin{array}{c}\text { Edible parts } \\
\text { (g/plant) }\end{array}$ & $\begin{array}{c}\text { Root/shoot } \\
\text { ratio }\end{array}$ \\
\hline YA & $0.56 \pm 0.023 \mathrm{a}$ & $6.50 \pm 0.31 \mathrm{a}$ & $1.68 \pm 0.080 \mathrm{a}$ & $8.14 \pm 0.34 \mathrm{a}$ & 4.20 \\
\hline CD & $0.38 \pm 0.018 \mathrm{c}$ & $4.99 \pm 0.27 \mathrm{~b}$ & $1.41 \pm 0.058 \mathrm{a}$ & $6.38 \pm 0.31 \mathrm{~b}$ & 3.81 \\
\hline YC & $0.47 \pm 0.019 \mathrm{~b}$ & $6.28 \pm 0.38 \mathrm{ab}$ & $1.55 \pm 0.074 \mathrm{a}$ & $7.81 \pm 0.42 \mathrm{a}$ & 4.35 \\
\hline CY & $0.43 \pm 0.020 \mathrm{bc}$ & $6.22 \pm 0.42 \mathrm{ab}$ & $1.50 \pm 0.062 \mathrm{a}$ & $7.60 \pm 0.21 \mathrm{ab}$ & 4.33 \\
\hline
\end{tabular}

$\mathrm{YA}=$ Ya'an, $\mathrm{CD}=$ Chengdu, $\mathrm{YC}=\mathrm{F} 1$ hybrid of Ya'an male $\times$ Chengdu female, $\mathrm{CY}=\mathrm{F} 1$ hybrid of Chengdu male $\times$ Ya'an female.

Table 2 Biomass heterosis rate of $\mathrm{F} 1$ generation $(\%)$

\begin{tabular}{|c|c|c|c|c|}
\hline Treatments & Roots & Tubers & Leaves & Edible parts \\
\hline YC & 0.00 & 9.22 & 1.54 & 7.58 \\
\hline CY & -9.3 & 8.17 & -2.60 & 4.68 \\
\hline
\end{tabular}

$\mathrm{YC}=\mathrm{F} 1$ hybrid of Ya'an male $\times$ Chengdu female, $\mathrm{CY}=\mathrm{F} 1$ hybrid of Chengdu male $\times$ Ya'an female.

Cadmium Content in Brassica juncea var. megarrhiza. The $\mathrm{Cd}$ content in roots of B. juncea var. megarrhiza from Ya'an had no significant differences compared with that from Chengdu (Table 3). The Cd contents in tubers, leaves and edible parts of $B$. juncea var. megarrhiza from Ya'an were significantly lower than that of Chengdu. The Cd content in roots of YC F1 hybrid had no significant differences compared with both two parents. The Cd content in tubers of YC F1 hybrid was higher than that of Ya'an parent, but had no significant differences compared with that of Chengdu parent. The Cd contents in leaves and edible parts of YC F1 hybrid had no significant differences compared with that of Ya'an parent, but were lower than that of Chengdu parent. The Cd contents in roots and tubers of CY F1 hybrid had no significant differences compared with both two parents. The Cd contents in leaves and edible parts of CY F1 hybrid had no significant differences compared with that of Ya'an parent, but were lower than that of Chengdu parent, which were the same as YC F1 hybrid. The TF of F1 hybrids were between two parents, which were higher than that of Ya'an parent and lower than that of Chengdu parent. The order of TF was ranked as Chengdu parent $>$ YC F1 hybrid $>$ CY F1 hybrid > Ya'an parent (Table 3).

The tuber biomass of YC F1 hybrid had the heterosis compared with both two parents, and the root, leaf and edible part biomasses of YC F1 hybrid had the hybrid weakness compared with both two parents (Table 2). The root, leaf and edible part biomasses of CY F1 hybrid also had the hybrid weakness compared with both two parents.

\section{Conclusions}

The reciprocal hybridizing of two genotypes of $B$. juncea var. megarrhiza had no obvious effects on biomass of F1 hybrids to some extent under Cd stress. The Cd contents in F1 hybrids of B. juncea var. megarrhiza were between two parents, which had no obvious reducing effects. Therefore, different genotypes of $B$. juncea var. megarrhiza hybridizing could had no obvious effects on enhancing biomass and reducing $\mathrm{Cd}$ content of $\mathrm{F} 1$ hybrids of $B$. juncea var. megarrhiza under $\mathrm{Cd}$ stress. In future work, investigations will focus on the tolerance mechanisms of $\mathrm{F} 1$ hybrids of $B$. juncea var. megarrhiza. 
Table 3 Cadmium content in Brassica juncea var. megarrhiza

\begin{tabular}{|c|c|c|c|c|c|}
\hline $\begin{array}{c}\text { Treatmen } \\
\text { ts }\end{array}$ & $\begin{array}{c}\text { Roots } \\
(\mathrm{mg} / \mathrm{kg})\end{array}$ & $\begin{array}{c}\text { Tubers } \\
(\mathrm{mg} / \mathrm{kg})\end{array}$ & $\begin{array}{c}\text { Leaves } \\
(\mathrm{mg} / \mathrm{kg})\end{array}$ & $\begin{array}{c}\text { Edible parts } \\
(\mathrm{mg} / \mathrm{kg})\end{array}$ & TF \\
\hline $\mathrm{YA}$ & $3.27 \pm 0.18 \mathrm{a}$ & $0.47 \pm 0.026 \mathrm{~b}$ & $0.91 \pm 0.060 \mathrm{~b}$ & $0.57 \pm 0.034 \mathrm{~b}$ & 0.24 \\
\hline $\mathrm{CD}$ & $3.40 \pm 0.22 \mathrm{a}$ & $0.63 \pm 0.044 \mathrm{a}$ & $1.29 \pm 0.077 \mathrm{a}$ & $0.77 \pm 0.051 \mathrm{a}$ & 0.32 \\
\hline $\mathrm{YC}$ & $3.15 \pm 0.21 \mathrm{a}$ & $0.58 \pm 0.038 \mathrm{a}$ & $0.99 \pm 0.071 \mathrm{~b}$ & $0.66 \pm 0.043 \mathrm{~b}$ & 0.27 \\
\hline $\mathrm{CY}$ & $3.00 \pm 0.19 \mathrm{a}$ & $0.55 \pm 0.033 \mathrm{ab}$ & $0.92 \pm 0.065 \mathrm{~b}$ & $0.62 \pm 0.044 \mathrm{~b}$ & 0.26 \\
\hline
\end{tabular}

$\mathrm{YA}=$ Ya'an, $\mathrm{CD}=$ Chengdu, $\mathrm{YC}=\mathrm{F} 1$ hybrid of Ya' an male $\times$ Chengdu female, $\mathrm{CY}=\mathrm{F} 1$ hybrid of Chengdu male $\times$ Ya' an female. The translocation factor (TF) is defined as (Cd content in shoots)/ $(\mathrm{Cd}$ content in roots).

Table 4 Cadmium content heterosis rate of F1 generation (\%)

\begin{tabular}{|c|c|c|c|c|}
\hline Treatments & Roots & Tubers & Leaves & Edible parts \\
\hline YC & -5.67 & 5.45 & -10.00 & -1.00 \\
\hline CY & -10.18 & 0.00 & -16.36 & -7.46 \\
\hline
\end{tabular}

$\mathrm{YC}=\mathrm{F} 1$ hybrid of Ya'an male $\times$ Chengdu female, $\mathrm{CY}=\mathrm{F} 1$ hybrid of Chengdu male $\times$ Ya'an female.

\section{Acknowledgements}

This work was financially supported by the 2016 Innovation Training Program of University Student (201610626032) and the Application Infrastructure Project of Science and Technology Department of Sichuan Province (2016JY0258).

\section{References}

[1] S.X. Jing: Horticultural Plant Breeding (Agricultural Press of China, Beijing, China 2007).

[2] L.P. Li, Z.W. Li, H.X. Yang, Q. Zhou, R.Y. Zhou and Z.G. Li: Guangxi Agricultural Sciences Vol. 43 (2012), p. 1291.

[3] J.P. He, C.H. Zhang, J.J. Chen, J.F. Mei, X.S. Chen and S.Q. Cao: Journal of Hefei University of Technology (National Science) Vol. 33 (2010), p. 1241.

[4] X.M. Zhu, W.Y. Yang, J.R. Shao and X.H. Chen: Seed Vol. 23 (2004), p. 3.

[5] C.S. Shang, B. Shi and S.H. Cheng: Acta Agriculturae Boreali-Sinica Vol. 7 (1992), p. 46.

[6] L.J. Lin, Q.H. Liu, J. Shi, J.L. Sun, M.A. Liao and L.Y. Mei: Environmental Toxicology and Chemistry Vol. 33 (2014), p. 1950.

[7] G.S. Liu: Soil Physical and Chemical Analysis \& Description of Soil Profiles (Standards Press of China, Beijing,China 1996).

[8] A. Caunii, A. Negrea, M. Pentea, I. Samfira, M. Motoc and M. Butnariu: Revista de Chimie (Bucharest) Vol. 66 (2015), p. 382. 